\title{
O ENQUADRAMENTO AXIOLÓGICO DO ENSINO DOS ESPORTES: PROBLEMAS E PERSPECTIVAS
}

\author{
FABIANO BASSO \\ Universidade Federal do Espírito Santo / Brasil \\ fabiano.basso@gmail.com \\ OtÁvio TAVARES \\ Universidade Federal do Espírito Santo / Brasil \\ tavaresotavio@yahoo.com.br
}

\section{Resumo}

Existe, tanto no senso comum quanto no âmbito acadêmico, consenso que o esporte educa. Mesmo as interpretações mais divergentes não excluem a noção de que o esporte, enquanto prática social significativa encontra-se relacionado a valores. Observa-se, porém, a ausência de uma reflexão sobre uma educação em valores para e na prática pedagógica. $O$ presente trabalho tem por objetivo problematizar o enquadramento axiológico do ensino de esportes a partir da mudança identificada de valores orientadores das formas de sociabilidade.

Palavras-chave: Esporte; Ensino; Valores.

\section{EL MARCO AXIOLÓGICO DE LA ENSEÑANZA DEPORTIVA: PROBLEMAS Y PERSPECTIVAS}

\section{Resumen}

Hay consenso que el deporte educa. Mismo las interpretaciones más divergentes no excluyen la noción del deporte como una práctica social relacionada a valores. Se puede observar la ausencia de una reflexión sobre la educación en valores en la práctica pedagógica y para la práctica pedagógica. El presente trabajo tiene como objetivo problematizar el marco axiológico en la enseñanza deportiva a partir del cambio identificado de valores que guían las formas de sociabilidad.

Palabras-clave: Deporte; Enseñanza; Valores.

\section{THE AXIOLOGICAL FRAMING OF TEACHING SPORTS: PROBLEMS AND PERSPECTIVES}

\begin{abstract}
There is, both in common sense and academic level, a consensus of sport as education. Even the more divergent interpretations do not exclude the notion of that sport, as social practice, is related to values. One could observe, however, the lack of a reflection about education on values to and at the pedagogical practice. The aim of this paper is the problematization of the axiological framing of teaching sports from the identified of change of guiding values of the forms of sociability.

Key-words: Sport; Teaching; Values.
\end{abstract}

\section{Introdução}


Ainda paira no senso comum a crença que o esporte educa, afasta as crianças do contato com as drogas, estimula um comportamento ético (fair play), que forma bons cidadãos, entre outras. Porém, a ausência de uma reflexão sobre uma educação em valores para e na prática pedagógica pode tornar esta premissa falsa.

Colocado em perspectiva histórica, os valores proclamados do esporte são o produto de forte influência do desenvolvimento do Movimento Olímpico. De fato, desde sua criação (1894) este movimento representou "a institucionalização da crença no esporte como um empreendimento moral e social" (Tavares, 2007: 184). Segundo este autor, "a maneira como praticamos e, principalmente, os valores que atribuímos a prática esportiva no século XX foram em grande medida formatados pelo Movimento Olímpico, apesar de seus impactos diferenciados e das diversas apropriações locais (Tavares, 2007: 185).

Se por um lado os valores que atribuímos ao esporte têm relações com o desenvolvimento do movimento olímpico, por outro, para diversos autores, este mesmo movimento representa a celebração dos valores da modernidade ocidental (Archetti, 1999; DaMatta, 2003; MacAloon, 1985). Avançando ainda mais nesta abordagem Tavares (2006), afirma que o esporte de um modo geral, e o esporte olímpico em particular combinam de maneira complexa valores iluministas (individualismo, universalismo, a crença no poder transformador da educação e o valor da competição) e valores românticos (honra, dever, autossuperação, fair play, senso de pertencimento e excelência moral).

Ainda que possa existir debate a respeito da definição do esporte como prática que surge na modernidade ou não (Stigger, 2002), não parece existir muita dificuldade em reconhecê-lo como um fenômeno significativo do mundo moderno. Todavia este consenso não indica de modo algum que se possa considerar a inexistência de divergência e debate a respeito de sua natureza, características, sentidos e funções. De fato, revisões como as de Bracht (2005b), Gaya et al. (2004), Heinemann e Puig (1991), Murad (2009) e Stigger (2002) indicam ser possível produzir visões e interpretações muito contrastantes a respeito das práticas esportivas. De todo o modo, as interpretações mais divergentes não excluem a noção de que o esporte, enquanto prática social significativa encontra-se relacionado a valores. Neste contexto, enquanto um conjunto de autores elaboram interpretações sobre o caráter do esporte como algo socialmente favorável à humanização (por exemplo, Gaya et al., 2004) ou favorável à alienação (por exemplo, Bracht, 2005b) a partir de um exame de seus valores proclamados tradicionais, outros examinam os efeitos de mudanças contemporâneas no sentido de considerá-lo como portador de um caráter "multicultural", (subjetivamente determinado) (Stigger, 2002) ou como um "sistema aberto" com escassa identidade própria (Heinemann; Puig, 1991) sendo, portanto, sujeito a um conjunto mais variado e contextualizado de valores. 
Em face do acima exposto, é possível questionar se os valores orientadores do esporte se mantém estáveis, ou se podemos pensar em uma superação dos valores do esporte moderno tradicional. Neste contexto, uma educação em valores por meio do esporte torna-se, qualquer orientação ou tendência, um desafio definido pelo possível desencaixe entre o sentido normativo das práticas educacionais e os valores e sentidos que os educandos atribuem ao mesmo. Para buscar a compreensão desta questão e dos possíveis novos enquadramentos axiológicos do esporte contemporâneo iremos abordar a discussão de valores e sua socialização através do esporte considerando interpretações sobre a contemporaneidade.

\section{Valores em perspectiva}

Desde os antigos filósofos e sofistas gregos existe uma discussão sobre valores. Platão, principalmente nos diálogos Mênon ${ }^{1}$ e Protágoras ${ }^{2}$, abordou o estímulo das virtudes para a formação do homem grego. DaCosta (et al., 2007: 13) resume de uma forma concisa a concepção dos antigos gregos sobre as virtudes:

Os helenos incentivavam, com grande ênfase, a aquisição do valor da transparência moral e do vigor físico (kalokagatia), privilegiavam as atividades atléticas como meio de educação, embora não usassem a expressão "valor", mas apenas julgamentos valorizativos. Ou seja, para os helenos o significado de "valor" não consistia em um termo sistematizado de conceitos e significados como é hoje, mas assumia um sentido de julgamento de comportamento expresso pelo termo "virtude" (comportamento bom, correto, honesto).

Aristóteles, em Ética a Nicômaco, ainda na linha platônica resume o porquê de envolver as virtudes com a formação do homem. Segundo o autor, a endaimonia ${ }^{3}$ seria o Bem Supremo, a qual seria conquistada através da prática da virtude. Segundo Immanuel Kant (2006), esta prática se dá pela Boa Vontade guiada pela Razão Prática. Esta razão é fruto da consciência do Dever (Lei Universal) manifestado pela Vontade. A representação de princípios objetivos que irão constituir a vontade, Kant (2006) denominou "mandatos" e que sua fórmula é o "imperativo"4 inclinação. Levando por fim à Liberdade, ou seja, saber obedecer. Podemos escolher entre obedecer aos nossos prazeres e nossas virtudes direcionadas para a tomada de consciência. Quando o homem se pensa como livre, inclui-se no mundo inteligível, conhecendo assim a autonomia da vontade com sua consequência: a moralidade.

\footnotetext{
${ }^{1}$ Diálogo que trata do ensino da virtude e da rememoração (anamnese).

2 Diálogo trata do conceito e natureza da virtude e sua possibilidade de ensinar (virtudes políticas).

${ }^{3}$ Felicidade Espiritual.

${ }^{4}$ Imperativo Categórico, ação somente conforme uma máxima que possa tornar-se Lei Universal (Kant, 2006).
} 
A moralidade também é amplamente pesquisada pela Psicologia Social. DaCosta (2007) faz uma revisão nas áreas de pesquisa da psicologia que remetem aos valores e esporte: a influência do esporte sobre o caráter e personalidade, comportamentos pró-sociais e atividade física, troca de valores quando da participação em esportes; na linha construtivista nas categorias: diferenças de raciocínio entre esporte e vida diária, participação esportiva e maturidade de raciocínio moral, raciocínio moral e tendências morais e educação moral. Porém, dois autores resumem muito bem essa temática. O primeiro é Lawrence Kohlberg com seus estágios de Julgamento Moral $^{5}$ sendo a consequência de formas de raciocínio e não conteúdos morais.

Como o julgamento moral de Kohlberg tem suas manifestações nas ações dos indivíduos? Pois, podemos ter certos valores e, às vezes, na ação nos contradizermos. Milton Rokeach (1981) oferece um sistema um pouco mais complexo sobre os valores. O autor define, sistematiza e separa: atitudes, crenças e valores. Crenças, atitudes e valores estão todos organizados juntos, de modo a formar um sistema cognitivo funcionalmente integrado, de maneira que uma mudança em qualquer parte do sistema afetará outras partes e culminará em mudança comportamental. Segundo este autor:

Considero valor como um tipo de crença, centralmente localizado no sistema total de crenças de uma pessoa, sobre como se deve ou não comportar, ou sobre algum estado final da existência alcançando, ou não, valor. Os valores são, assim, ideais abstratos, positivos ou negativos que, não-atados a nenhum objeto ou situação de atitude específica, representam as crenças de uma pessoa sobre os modos ideais de conduta e objetos terminais ideais (Rokeach, 1981: 100).

Rokeach (apud Sanmartín, 1995) entende que os valores são adquiridos através dos processos de socialização e de transmissão entre os seres humanos. Considera, por tanto, que tudo quanto se faça ao redor de uma criança incidirá no processo de formação de sua personalidade. Daí que os diferentes sistemas de educação influirão nos valores que a criança desenvolva. Reaproximando esta discussão do âmbito da questão da socialização e do esporte,

Não podemos perder de vista que o esporte é uma prática corporal construída, vivenciada e modificada na interação dos homens na cultura, refletindo seus valores e gerando novos; sua forma e constituição dependerão sempre dos objetivos atribuídos a ele. Logo, cabe-nos ressaltar que os valores não são essencialmente do esporte, mas se refletem no esporte e são também gerados a partir dos significados que os indivíduos e grupos sociais dão à prática esportiva (DaCosta et al., 2007: 15).

Assim, podemos dizer que através de uma educação em valores por meio do esporte tem-se uma peça fundamental para socialização.

\footnotetext{
${ }^{5}$ Ver Biaggio, A. (2006). Lawrence Kohlberg: ética e educação moral. 2. ed São Paulo: Moderna.
} 
Segundo Dubar (2005), a socialização é a construção de um "mundo vivido" podendo ser desconstruído e reconstruído ao longo da existência. Produzindo identidades de atores que não se reduzem nem a habitus de classe nem a esquemas culturais. Como afirmam Boudon (1996) e Cuche (1999), por exemplo, o processo de socialização envolve tanto a transmissão de valores orientadores para a ação socialmente determinados quanto a maneira como os indivíduos ressignificam estes valores segundo um quadro de influências complexo. Segundo Nadel (1987), isto é possível pela existência do que ele chama de espaços intersticiais entre os sistemas sociais. Tais teorizações nos permitem mudar nosso foco da questão de como as sociedades se mantém para como as sociedades se transformam.

Se isto é verdade, retomando a afirmativa de que os valores da sociedade são refletidos no esporte e "também gerados a partir dos significados que os indivíduos e grupos sociais dão à prática esportiva" (DaCosta, 2007: 15) podemos pensar que os valores do esporte também estão em mudança. Neste ponto, duas questões podem ser definidas: Que sinais e sintomas de mudança de valores apresentam as sociedades contemporâneas? Que sinais e sintomas de mudança de valores orientadores apresentam as práticas esportivas contemporâneas? Que valores orientam as práticas esportivas contemporâneas?

\section{Sociedade contemporânea e os possíveis enquadramentos axiológicos das práticas esportivas}

Parece ser possível aceitar que a sociedade apresenta mudanças que começaram sutilmente a aparecer e estão migrando para alguns focos de ação dos indivíduos. Os amos da Caverna ${ }^{6}$ a deixaram mais confusa, seu labirinto aumentou e o Minotauro perdeu seu sentido, encontrá-lo e matá-lo não tem mais um objetivo final, assim, sendo esquecido. Bauman (2001) apresenta a dita "modernidade líquida" e sua característica patológica política: "o esvaziamento e a decadência da arte do diálogo e da negociação, e a substituição do engajamento e mútuo comprometimento pelas técnicas do desvio e da evasão" (Bauman, 2001: 127). O autor interpreta que a "modernidade líquida" gera uma incerteza por causa de sua fluidez e do seu curto prazo. Assim, surge a demanda de uma invidualização, com a ideia do interesse comum perdendo o seu valor prático. Este desengajamento unilateral enfraquece os laços de trabalho e de relacionamentos.

Rouanet (1998) analisa e estabelece as características da pós-modernidade nos âmbitos: social, com uma manifestação (no cotidiano) de "uma onipresença do signo e do simulacro, do vídeo e da hipercomunicação"; "econômico, por uma planetarização do capitalismo (com suas correspondentes manifestações superestruturais, inclusive a cultura informatizada"; e político, "por um Estado que busca no passado modelos de uma inocência perdida e por grupos segmentares que explodem em mil estilhaços o campo da política moderna" (Rouanet, 1998: 238).

${ }^{6}$ Ver Platão, República. Livro VII. Mito da Caverna. 
Nessa caminhada para a "separatividade" e a "individualização", Rouanet (1998), afirma que a modernidade

Com sua bandeira mais alta, a da razão, está sendo contestada. Sua fé na ciência é denunciada como uma ingenuidade perigosa, que estimulou a destrutividade humana e criou novas formas de dominação, em vez de promover a felicidade universal. A crença no progresso expôs o homem a todas as regressões. Seu individualismo estimulou o advento do sujeito egoísta, preocupado unicamente com o ganho e a acumulação. A crença na mudança das relações sociais como forma de implantar o paraíso na Terra levou a uma utopia concentracionária, e resultou na criação de todos os gulags. Sua cruzada desmistificadora solapou as bases de todos os valores, deixando o homem solitário, sob um céu deserto, num mundo privado de sentido (Rouanet, 1998: 26-27).

Giddens (1991) complementa o entendimento doa tempo presente, também chamado de "pósmodernidade" quando diferencia as três fontes que dominam a dinâmica da modernidade. A primeira, a separação entre tempo e espaço que tem um alvo indefinido. A segunda, o desenvolvimento de mecanismos de desencaixe. A atividade social é deslocada dos contextos localizados gerando relações sociais de grandes distâncias tempo-espaciais. E a terceira, a apropriação reflexiva do conhecimento na qual "a produção de conhecimento sistemático sobre a vida social torna-se integrante da reprodução do sistema, deslocando a vida social da fixidez da tradição" (Giddens, 1991: 59). A reflexividade da modernidade significa que as práticas sociais são enfocadas, organizadas e transformadas, à luz do conhecimento constantemente renovado sobre estas próprias práticas.

Assim, segundo o autor, o contexto geral da modernidade se resume às relações de confiança em sistemas abstratos desencaixados. Este ambiente de confiança se centraliza em relações pessoais de amizade ou intimidade sexual como meios para gerar estabilidade dos laços sociais; em sistemas abstratos como meios de estabilizar relações através de extensões indefinidas de tempo-espaço; e, em um pensamento contratual orientado para o futuro como um modo de conectar passado e presente. $\mathrm{O}$ autor também caracteriza o ambiente de risco da modernidade com ameaças e perigos emanando da reflexividade da modernidade, a ameaça de violência humana a partir da industrialização da guerra e a ameaça da falta de sentido pessoal derivada da reflexividade da modernidade enquanto aplicada ao eu. O autor ainda complementa quando afirma que a sociabilidade acopla-se analogamente às instituições abrangentes de distanciamento tempo-espaço em relação à lealdade e autenticidade das relações pessoais (Giddens, 1991).

Dando o último acorde sobre a "pós-modernidade", Rouanet (1998: 269) afirma que esta é uma "fadiga crepuscular de uma época que parece extinguir-se ingloriamente que o hino de júbilo de amanhãs que despontam. À consciência pós-moderna não corresponde uma realidade pós-moderna. Nesse sentido, ela é um simples mal-estar da modernidade, um sonho da modernidade". 
A esse mal-estar, ou como cita Giddens (1991), estas consequências da modernidade, são nada mais do que Rouanet (1998) designa a situação contemporânea, a chamada neomodernidade. A neomodernidade, de uma forma sucinta, pode ser caracterizada por sua incerteza (Bauman), sua radicalização da fase atual da modernidade (Giddens), ou a incompletude de seu projeto (Rouanet). Suas pressões estão gerando um descolamento e surgimento de valores. Neste contexto, tais elaborações oscilariam entre uma generalidade formal cada vez maior e reapropriações específicas segundo os códigos e demandas dos grupos e instituições que os organizam.

O atrito de valores de duas gerações é um catalisador da mudança e ressignificação. Porém, com o advento da neomodernidade, o pluralismo de valores promove a incerteza "especialmente entre aqueles que necessitam mais fortemente de uma bússola axiológica, como é o caso dos jovens." (Queirós, 2004: 189). Assim, segundo a autora,

cada uma das crianças, dos adolescentes e dos jovens, carece fundamentalmente de encontrar no desporto (ou na pluralidade dos desportos), acompanhamento e sinais claros para a sua própria orientação, mas num modelo coexistencial de desporto, onde caiba o respeito pela identidade de cada um, pelo diferente e complementar, enfim, pela pessoa de cada um (Queirós, 2004: 190).

O desinteresse pelo coletivo levou muitos jovens a perder seu interesse nas aulas de educação física escolar ${ }^{7}$, preferindo atividades físicas na academia, esportes de aventura, de contato com a natureza, atividades individuais, fitness, frequentemente tendo como motivação a individualização, o lazer, e/ou entretenimento. Esse fato parece ser o reflexo do homem neomoderno, pois, agora, seu individualismo se concentra no corpo. Essa limitação "é mais um sintoma da vaga individualista dos tempos pós-modernos” (Lipovetsky apud Queirós, 2004: 192). Tavares (2007: 193) considera que atualmente pode estar ocorrendo uma "atomização dos valores das práticas esportivas e a predileção dos esportes individuais e alternativos em detrimento dos esportes coletivos tradicionais".

Neste contexto, Le Breton (2009) sugere que a sociabilidade ausente é recriada e ressignificada, abrindo em si mesmo uma espécie de diálogo que assimila o corpo à possessão de um objeto familiar, sendo uma forma possível de transcendência pessoal e de contato. Surge um novo público, aquele que não tem interesse nos esportes coletivos e seus valores sociais, mas sim em manter sua saúde e buscar sua excitação sozinhos, no seu horário, na sua preferência, no seu esquema pessoal. E isso está cada vez mais se difundindo dentre as identidades jovens. Principalmente nos esportes e atividades físicas de risco/aventura, floresce o desejo por essas práticas, que "nasce da profusão dos sentidos que o mundo contemporâneo sufoca" (Le Breton, 2009: 88). A possível fonte deste desejo pelo risco é a "perda de

\footnotetext{
${ }^{7}$ Devemos aceitar, porém que as razões que levam ao desinteresse pela educação física são muitos e complexos.
} 
legitimidade dos referenciais de sentido e de valores, sua equivalência geral numa sociedade onde tudo se torna provisório, desestabiliza o panorama social e cultural” (Le Breton, 2009: 88).

Como afirma Pais (apud Queirós, 2004: 192):

os jovens abraçam valores de expressividade, de sedução, de hedonismo, combinando o prazer na vida sexual com o prazer no trabalho, o prazer com os amigos, etc. [...] As éticas sociais com marcado cunho puritanista (com os seus partidários do trabalho, da poupança, da submissão, do controlo e da disciplina), e que orientam as gerações mais velhas, estão a dar lugar, paulatinamente, a éticas individualistas com marcado cunho hedonista (desfrute da vida, consumismo, ilusões, fantasias e desejos), predominantemente entre os jovens.

Assim, "não vivemos, pois numa sociedade cega perante os valores, mas sim numa sociedade com tantos valores que se torna difícil ou impossível diferenciar o valor do antivalor" (Gervilla apud Queirós, 2004: 191). Temos aqui um problema central para a construção de uma solução socialmente significativa para o ensino em valores por meio do esporte.

\section{Concluindo}

Educar em valores através do esporte é um dos eixos da Educação Física Escolar. Sabemos que “devemos entender que o movimento que a criança realiza num jogo tem repercussões sobre todas as dimensões do seu comportamento, e mais, que esta atividade veicula e faz a criança introjetar determinados valores e normas de comportamento" (Bracht, 2005a: 66).

Entretanto, como isto pode ser objetivamente sistematizado? Sanmartín (1995: 165) nos indica um caminho quando afirma que

a aprendizagem das orientações de comportamento ou valores que em uma determinada sociedade se consideram apropriados, se realiza, pelo menos, de quatro modos diferentes: por associação, por imitação, por comunicação e por persuasão. Destes, os dois primeiros são atividades de aprendizagem que normalmente correspondem à infância e juventude. Pelo contrário, a comunicação e a persuasão requerem níveis mais complexos de funcionamento cognitivo e consciência. Mediante estas atividades aprendemos tanto as condutas adequadas que de nos se esperam, como as razões que apóiam ditas condutas.

Porém, a intervenção pedagógica em valores enfrenta alguns obstáculos. O primeiro se caracteriza por uma falta de consenso entre investigadores e professores sobre quais são os valores a serem ensinados e sua definição (o valor não é um significado claro, mas o que se tem em consenso é que valor representa algo importante para a existência humana). O segundo engloba a dificuldade para determinar que efetividade tem tido a atividade física como veículo de aprendizagem no desenvolvimento em valores. $\mathrm{O}$ terceiro se refere à carga horária escolar limitada para estruturar a 
atividade física e esportiva, somando a falta de compreensão e ajuda da comunidade educativa no que se refere ao desenvolvimento dos valores. E o quarto abrange a falta de instrumentos eficazes para uma educação objetivada em valores por meio da atividade física e do esporte.

Segundo Queirós (2004: 189):

para equacionar a questão dos valores na participação no desporto das crianças e jovens de hoje, necessitamos então perceber qual o enquadramento axiológico social contemporâneo, que valores nos aparecem associados ao desporto de hoje e fundamentalmente não esquecer "a quem" tudo isto se destina.

Surge então, uma demanda de pesquisa e reflexão sobre os valores sociais dos diferentes segmentos da juventude e suas orientações em relação às práticas esportivas. Sob qualquer orientação normativa, qualquer projeto de dever-ser objetivado, o ensino em valores por meio do esporte demanda uma práxis educativa que, ao mesmo tempo, supere a crença inocente de que a prática esportiva per se já garante a educação que se pretende alcançar e desenvolva os instrumentos didáticos e a prática pedagógica necessários para, como diria Platão, alimentar as almas dos homens. Os valores que humanizam o homem.

\section{Referências}

ARCHETTI, E. (1999). The spectacle of heroic masculinity: Vegard Ulvang and Alberto Tomba the Olympic Winter Games of Albertville. In: Olympic games as performance and public events: The case of the XVII Winter Games in Norway, New York: Berghan Books.

BAUMAN, Z. (2001). Modernidade líquida. Rio de Janeiro: J. Zahar.

BRACHT, V. (2005a). Educação Física e Aprendizagem Social. Porto Alegre: Magister. . (2005b). Sociologia Crítica do esporte: uma introdução. Ijuí: Ed. Unijuí.

BOUDON, R. (1996). Tratado de Sociologia. Rio de Janeiro: Zahar.

CUCHE, D. (1999). A noção de cultura nas ciências sociais. Bauru: EDUSC, 1999.

DACOSTA, L. et al. (2007). Manual valores do esporte - SESI: fundamentos. Brasília: SESI/DN.

DAMATTA, R. (2003). Em torno da dialética entre igualdade e hierarquia: notas sobre as imagnes e erepresentações dos Jogos Olímpicos e do Futebol no Brasil. Antropolítica: Revista contemporânea de Antropologia e Ciência. Niterói, n. 14, p. 17-39, 1 sem. 
DUBAR, C. (2005). A socialização: construção das identidades sociais e profissionais. São Paulo: Martins Fontes.

DUNNING, E. (1992). A dinâmica do desporto moderno: notas sobre a luta pelos resultados e o significado social do desporto. In: A busca da excitação. Lisboa: DIFEL, p. 299-325.

ELIAS, N. (1992). Ensaio sobre o desporto e a violência. In: Elias, N.; Dunning, E. A busca da excitação. Lisboa: DIFEL.

GAYA, A. et al. (2004). Desporto para crianças e jovens: razões e finalidades. Porto Alegre: Ed. da UFRGS.

GIDDENS, A. (1991). As conseqüências da modernidade. 2. ed. - São Paulo: UNESP.

HEINEMANN, K.; PUIG, N. (1991). El deporte en la perspectiva de año 2000. Papers, n. 38, p. 123141.

KANT, I. (2006). Fundamentação da metafísica dos costumes e outros escritos: texto integral. São Paulo: Martin Claret.

LEBRETON, D. (2009). A sociologia do corpo. Rio de Janeiro: Vozes.

MACALOON, J. (1984). Olympic games and the theory of spectacle in modern society. In: Rite, drama, festival, spectacle. ISHI Press, p. 241-280.

MURAD, M. (2009). Sociologia e Educação física: diálogos, linguagens do corpo, esportes. Rio de Janeiro: Ed FGV.

NADEL, S. (1987). Compreendendo os povos primitivos. In: Antropologia das sociedades contemporâneas: métodos. São Paulo: Global.

QUEIRÓS, P. (2004). Para um novo enquadramento axiológico na participação de crianças e jovens no desporto. In: Desporto para crianças e jovens: razões e finalidades. Porto Alegre: Ed. da UFRGS, p. 187-198.

ROKEACH, M. (1981). Crenças, atitudes e valores. Rio de Janeiro: Ed. Interciência.

ROUANET, S. P. (1998). As razões do iluminismo. São Paulo: Companhia das Letras.

SANMARTÍN, M. G. (1995). Valores sociales y deporte: la actividad física y el deporte como transmisores de valores sociales y personales. Madrid: Gymnos.

STIGGER, M. (2002). Esporte, Lazer e estilos de vida. Campinas: Autores Associados.

TAVARES, O. et al. (2006). Estudos Olímpicos, Academia Olímpica Brasileira e Educação Olímpica. In: Atlas do Esporte no Brasil. Rio de Janeiro: Sprint.

(2007). Valores Olímpicos no século XXI. In: Ética e compromisso social nos estudos olímpicos. Porto Alegre: EDIPUCRS. 
